\title{
Exchange
}

\section{Self-Determination for Individuals With Significant Cognitive Disabilities and Their Families}

\author{
Ann Turnbull and Rud Turnbull \\ University of Kansas
}

We write this article as parents of our 33 year old son, JT, who has significant mental and emotional disabilities, and as professionals in the field of developmental and mental health disabilities. We write about self-determination, a value that we practice in our own lives and a value that we want JT (and our two daughters) to practice in theirs. In short, we want to take control of our lives in an independent fashion. We want JT to do likewise and we applaud the way our daughters have done so. But with JT, unlike ourselves and our daughters, taking control, being self-determined, is a curiously lived value. To continue to honor his obvious choice to live "in my own home," we have just purchased a different house for JT (he had been living in another home of his own for 11 years) that would enable him to live with "primary" and "weekend" housemates who would provide support 24 hours a day, 7 days a week. The house has two separate living areas and is over 3,000 square feet. When we asked JT how much the house cost, he said, "\$1.00." When we asked him what he thinks about it, he answered, "Nice." When we asked him whether he wanted to move back to our family home, he said, "No." When we asked him what is necessary to maintain his house in good order, he said, "Work." Our probes of his meanings were no more revealing than his original answers.

Because they reveal so dramatically aspects of his cognitive disability and the functional limitations that attend it, JT's responses provide a context for discussing the role of families in supporting the self-determination of individuals with significant cognitive disabilities. The issues are manifold: What does self-determination mean for people whose limitations are like JT's? When, how, and how much can and should families recede in quality of life decision making from their children or other members with such disabilities? These and related issues challenge us as parents and as professionals. We write

Address all correspondence and requests for reprints to Ann Turnbull, Beach Center on Families and Disability, University of Kansas, 3111 Haworth Hall, 1200 Sunnyside Ave., Lawrence, KS 66045-7534. E-mail: turnbull@ukans.edu in both capacities, but to a largely professional audience, to tease out the implications of these issues and to make recommendations for research, partnerships, and service provision.

Key Issues in Self-Determination for People With Significant Cognitive Disabilities and Their Families

We address two key issues in self-determination for people with significant cognitive disabilities and their families. First, inadequate attention has been given to the profound influence of significant cognitive disabilities on achieving self-determination. Second, selfdetermination is a heavily culturally laden concept and cultural values influence one's definition of selfdetermination (Turnbull \& Turnbull, 1996, 2001).

\section{Influence of Significant Cognitive Disability}

Consider the matter of self-determination for individuals with significant cognitive disabilities (as defined by the American Association on Mental Retardation [AAMR], Luckasson et al., 1992). Clearly, these individuals almost always require extensive or pervasive decision making supports (i.e., motivation, resources, skills, and responsive contexts) to experience quality of life consistent with their own values, preferences, strengths, and needs. Experiencing quality of life with such consistency is how we define self-determination (Turnbull \& Turnbull, 1985,1996). However, most definitions of selfdetermination attribute to individuals with disabilities the role of a causal agent in making decisions in their lives and presume that their action exists (or should exist) free from undue external influences (Wehmeyer, 1998; Wehmeyer, Agran, \& Hughes, 1998). Professional practice and good sense compel the conclusion that individuals with significant cognitive disabilities must choose, to the extent that they are able (with the appropriate degree of extensive or pervasive support), the trusted allies with whom to collaborate or 
on whom to depend for decision making support. Typically, trusted allies have the most committed emotional relationship with the individual with a disability (e.g., parents, siblings, other family members, friends, and service providers). When people with significant cognitive disabilities are unable to determine the people with whom they want to collaborate or on whom they want to depend, then people with the most emotionally connected relationships with the individual should step forward to provide support in initially selecting the trusted allies. Therefore, the first step in actualizing selfdetermination for people with significant cognitive impairments is to recognize the functionality (or lack of functionality) associated with their impairments and to respond by building alliances that advance their selfdetermination.

The next step in actualizing self-determination is for those allies to collaborate with the individual with significant cognitive disabilities in deciding the nature and intensity, of support in making and then, acting on decisions. There may be a substantial gap between the decisions that need to be made/acted upon and the individual's cognitive ability (e.g., buying a house). When this occurs, the trusted allies' task is one of "standing in the shoes" of the person with significant cognitive disabilities (Boggs, 1985). They must make the decisions that they believe the person would make, given his or her values, preferences, strengths, and needs, if he or she had the cognitive ability (i.e., motivation and skills) necessary to make the decisions.

Putting these theoretical arguments aside, their real world limitations must be acknowledged: Individuals with significant cognitive disabilities often have not experienced authentic membership in the self-advocacy movement and have not been sufficiently included in many of -the selfdetermination demonstration models (Bambara, Cole, \& Koger, 1998; Wehmeyer, 1998; Wehmeyer \& Sands, 1998). Some people may not recognize that significant cognitive disabilities truly make a difference in the ability of an individual to be self-determining without extensive support of other people. In fact, we doubt that most individuals with significant cognitive disabilities are able to control the decisions in their lives without undue external influences. Consider what Elizabeth Boggs (1985) wrote about the needs of her son, David, who had profound mental disabilities:

In a recent large meeting a well-known superintendent who runs a facility in which there are residents like David remarked that they had recently placed a number of profoundly retarded adults in the community, and that when these profoundly retarded adults were asked whether they would like to return to the institution, they all said no. I am sure that the adults to whom he referred were successfully placed, and I do not doubt their capacity or the lack of coercion in their response.
However, if people who could make such a conceptual choice, who could understand the question and express an answer are called profoundly retarded, then we need some new term for those who cannot do any of these things. (pp. 49-50)

If the first key issue is defining self-determination for individuals with significant cognitive disabilities (and also recognizing, as Boggs did, that the extent of disability can make all the difference in how we think of "selfdetermination" and for whom it can exist, for it did not exist for David), then the second is to honor family and individual choices that reflect the influence of cultural values.

\section{Influence of Cultural Values}

Many definitions of self-determination are rooted primarily in an Anglo European ethnic orientation (Hanson, 1998; Kalyanpur \& Harry, 1999). Table 1 provides contrasting beliefs, values, and practices between . a generalized Anglo European perspective and a generalized perspective of many other ethnic groups that are not as dominant in the United States. Given that approximately $90 \%$ of special education professionals are of Anglo European descent, it is easy to see why special education professionals strongly support self-determination (Hill, 1993).

It bears repeating that, consistent with our definition of self-determination, the process of choosing how to live one's life should respect and honor the family cultural values including values pertaining to parental authority over child choice and collectivism over individualism. We recall a Hispanic mother explaining her views about selfdetermination and her gifted son's individualized education plan (IEP) meeting (Turnbull \& Turnbull, 1997):

Here in the United States it is like you always ask the child first, and for us it's, very important for us

Table 1 Contrasting Beliefs, Values, and Practices

\begin{tabular}{|c|c|}
\hline Anglo-European & Other cultures \\
\hline $\begin{array}{l}\text { Personal control over the } \\
\text { environment }\end{array}$ & Fate \\
\hline Change & Tradition \\
\hline Time dominates & $\begin{array}{l}\text { Human interaction } \\
\text { dominates }\end{array}$ \\
\hline Human equality & Hierarchy/rank/status \\
\hline Individualism/privacy & Group welfare \\
\hline Selfhelp & Birthright inheritance \\
\hline Competition & Cooperation \\
\hline Future orientation & Past onientation \\
\hline Action/goal/work orientation & "Being" orientation \\
\hline Informality & Formality \\
\hline Directness/opennesshonesty & Indirectnessyitual/face" \\
\hline Practicality/efficiency & Idealism/theory \\
\hline Materialism & Spiritualism/detachment \\
\hline
\end{tabular}


as a parent to participate. And so the way that they handle those IEP meetings is like the American people, and they're not considering Chinese or Hispanic or any other culture. I know that it's not on their mind, but it really hurts our feelings....We tell our children more what to do, what's wrong, what's right, and maybe we don't develop that independence ... and maybe we start doing that after they turn 19 or 20 . When we came to the United States five years ago, my children felt that difference in their education from school and home. They didn't understand very well what was going on; why we were one way at home [in asserting parental authority] and the teachers treated them in a different way [offering them more choices]. (p. 237)

As parents of JT, our parental values (and the values of our two daughters) very much coincide with the data it Table 1 (Anglo European beliefs, values, and practices), that is, the foundational values of self-determination. However, as we analyze the data in Table 1 and think about JT, it is clear that JT is more orientated toward the "other culture" column in many ways than the Anglo European. For him, human interaction dominates over time; tradition dominates over change; "being" orientation dominates over action goal/work orientation; and indirectness/ritual dominates over directness/openness. A primary source of hi, perspectives is the extent of his cognitive (and emotional) disabilities. In a sense, he marches on a different path and to the beat of a different drummer. In our family, parental and sibling culture on the one hand and JT's individual culture on the other sometimes play different tunes and march on different paths. Each must be taken into consideration in appropriately operationalizing selfdetermination.

If self-determination means living one's life consistent with one's own values, preferences, strengths, and needs and implicitly doing so free from external influences, then we have to admit that JT, because of his cognitive (and emotional) disabilities, is significantly advanced and also significantly limited in being universally self-determined. He is advanced in that he communicates and acts on his preferences, especially around "easier" decisions pertaining to dress, eating, schedule, community participation, friendships, and work tasks. He is limited, however, in that he does not have the skills and motivation for the very hard work-the thinking and acting-that is involved in taking control of his life, especially in terms of complex decisions related to finances, health care, running a household, scheduling activities, and arranging for and supervising personal support. When his decisions about life (i.e., his selfdetermination) pose unacceptable risks, irreversibility, and intrusiveness, the potentially adverse consequences of his (self-determination) decisions can be high and require both greater scrutiny (Turnbull, Bilklen, Boggs, Ellis, Keeran, \& Siedor, 1977) and greater support (Dinnerstein, Herr, \& O'Sullivan,1999; Luckasson et al., 1992).

Having identified the advanced and limited dimensions of JT's (paradigmic) self-determination, let us also acknowledge that JT's conception of selfdetermination is fundamentally correct, according to our definition: experience quality of life consistent with his own values, preferences, strengths, and needs. But there is an irony. In his self-determination, he also expects his parents, siblings, grandfather, housemates, job coach, and. friends to engage in complex decision making to ensure that he lives his life the way that he wants to live it.

Interestingly, he not only expects us to ensure that his lifestyle is as he wants it to be, he absolutely insists on it. He has two very effective assertiveness strategies when all else fails, that is, highly preservative language and acute problem behavior. His absolute insistence holds us to the highest standard of accountability that we have experienced in any domain in our lives, including all professional domains and their associated standards of licensure, promotion, tenure, and peer and consumer accountability. No professional peer reviewer has been nearly as exacting about our writing on comprehensive positive behavioral support as JT is about our providing that kind of support. To repeat: JT's control over some (most) decisions is not to be found innately (i.e., in his own capability to make complex decisions). Rather, it is to be found in his behaviors. If they are indeed surrogates for communication, then JT is a most self-determined person. He "fights his corner" steadfastly in demanding to live his life the way that he wants to live it. JT teaches us that self-determination means different things to, and is manifest in different ways by, different people. For JT, his significant cognitive disabilities make a huge difference in his capacities for complex decision making and his cultural values are not nearly as oriented toward personal control, individualism, self-help, and efficiency as they are for other members of his family. Yet, it is clear to all who know him that he is a highly self-determined man.

\section{Self-Determination, Quality of Life, and Lifespan Challenges}

We regard self-determination as the means for experiencing quality of life consistent with one's own values, preferences, strengths, and needs. The challenges are to develop a self-determined vision of quality of life (e.g., now, when JT is 33), actualize the vision in daily routines and relationships, and make quality of life adjustments and enhancements over the full lifespan (e.g., when JT retires). Five lines of work should merge to enable families and individuals with significant cognitive 
disabilities and their trusted allies to address these challenges. Interestingly, two of these initiatives are called self-determination, but the meaning of that term is very different for each.

The first line of research focuses on the quality of life of individuals with disabilities (Felce, 1997; Gardner \& Nudler, 1999; Schalock, 1996, 1997, 2000). It is directed at enabling individuals with disabilities to specify their perspectives on the quality of life domains and the indicators to which they attach importance and with which they are satisfied or dissatisfied as a guide for service delivery planning and monitoring. It is our impression that this research has primarily involved individuals with cognitive disabilities who, unlike Elizabeth Boggs's son David, are able to make conceptual choices, understand questions, and express answers.

The second line of research investigates ways to conceptualize and evaluate the quality of life of families (e.g., parents, siblings, grandparents) of individuals with disabilities (Brown, 1996; Renwick, Brown, \& Nagler, 1996; Turnbull \& Turnbull et al., 2000; Turnbull, BlueBanning, Turbiville, \& Park, 1999). In July 2000, researcher-parent teams from five countries convened in a family quality of life symposium. This event took place just prior to the International Association for the Scientific Study of Intellectual Disability Congress to share conceptualizations, approaches to and risks of measurement and evaluation issues, and future research agenda in early efforts to provide ways to document family quality of life perspectives. The conceptualization and research agenda around family quality of life need to converge with the conceptualization and research agenda around individual quality of life so that compatible models are possible. (As researchers, we recognize the difficulties of measuring family quality of life. As parents and advocates, we fully acknowledge and will guard against the potentially deleterious effects of any measurement initiatives. We do not need to revisit the "Baby Doe" matters that a prominent ethicist dredged up recently.)

The third line of research concerns positive behavioral support and its role in developing comprehensive lifestyle support for individuals with problem behavior (Carr et al., 1999; Horner \& Carr, 1997). Although the positive behavioral support literature emphasizes developing comprehensive lifestyle support, this criterion has been measured for less than $3 \%$ of the research participants over the last decade (Carr et al., 1999). Individuals with significant cognitive disabilities experience problem behavior. A major intervention focused within positive behavioral support is to maximize their choices and preferences. It stands to reason that positive behavioral support research could be enhanced by the quality of life and self-determination research efforts.

The fourth line of research focuses on selfdetermination as the psychological process of develop ing motivation and skills to choose how to live one's life. Tremendous progress has been made over the last 10 years in advancing self-determination motivation and skills (Wehmeyer et al., 1998; Wehmeyer \& Sands, 1998). There is overlap between the concepts of choice and preference in the positive behavioral support literature and the self-determination emphasis on behavioral autonomy, self-regulated behavior, psychological empowerment, and self-realization (Wehmeyer, 1999). The research on elfdetermination can help to explicate the quality of life priorities for individuals with significant cognitive disabilities and their families.

The fifth line of research, currently sponsored by the Robert Wood Johnson Foundation, is a national selfdetermination effort to fund individuals with disabilities and their families to enable them to afford the quality of life that they envision (Nerney, 1999; Shumwav, 1999).. In our conceptualization of self-determination, individualized funding corresponds to the elements of having motivation and resources and being supported by responsive environmental contexts. Currently being implemented in approximately 19 states, this approach redirects funding from agencies to individuals with disabilities and their families. Many families, professionals, and individuals with significant cognitive disabilities cannot envision anything different in the service configuration than what the provider system traditionally has provided. Thus, there appears to be a major need for better procedures and processes for enabling individuals with significant cognitive disabilities and their families to choose how to live their lives (Wehmeyer, 1999).

A merger of these five lines of research could assist service agencies, individuals with significant cognitive disabilities, and trusted allies to:

- Take stock of what is important to them in terms of individual and family quality of life across all domains.

- Determine what is in place now that is consistent with their values, preferences, strengths, and needs.

- Determine what needs to change to create a better match between individual and family values, preferences, strengths, and needs and what currently exists.

- Develop action plans to implement extensive or pervasive supports and services tied to priority individual and family quality of life criteria.

- Actualize the supports through individualized funding so that quality of life preferences can be financially brought to fruition (Turnbull, et al., 1999).

Over the last year, we have been involved as a family in this "quintuple effort" to maximize individual and family quality of life, especially around issues of problem 
behavior, through the self-determination funding option. We have done a better job of addressing the tasks ourselves than of actively ensuring that JT will advance his selfdetermination through his own active participation in making complex decisions. It has been a daunting responsibility for us, in spite of the fact that among us we have six university degrees and about 50 years of experience in the disability field.

We have had to address the following issues:

1. Qualifying JT for the Medicaid Waiver (proving the nature and extent of his disabilities-for the umpteenth time!).

2. Suing the state to overturn its decision that a trust fund benefiting JT eliminates him from Medicaid eligibility.

3. Understanding the services and supports that the Medicaid Waiver will reimburse and meeting on countless occasions with state and local decision makers to incorporate specifics into an ambiguous process.

4. Proceeding through several administrative hearings before the state was required to make JT eligible.

5. Having numerous meetings with the local MR/ DD agency about JT's status on its Medicaid waiting list.

6. Maximizing JT's funding package by exploring and finally obtaining SSDI eligibility.

7. Doing the same under the Section 8 housing program.

8. Having numerous meetings with realtors to explore various housing options customized to JT's supported living preferences and needs.

9. Researching and securing the most advantageous mortgage rates for JT and his housemates.

10. Researching city regulations regarding zoning pertaining to the number of unrelated individuals who can live in a house.

11. Calculating long-term finances and support needs regarding income received and income expended.

12. Working with current housemates and others who have expertise on the best ways to support housemates to maximize their quality of life (another monumental issue that is inextricably tied to the quality of life of the individual with a significant cognitive disability and the individual's family).

13. Creating and implementing a 24/7 "Rolls Royce" system of positive behavioral supports across all environments.

14. Working with numerous consultants to try to identify the medication regiment to provide the most beneficial results possible, taking into account JT's heart condition (atrial fibrillation) and mental health issues (rapid cycling bipolarity and obsessive compulsive disorder).

15. Keeping all family members informed, considering their preferences, listening to and trying to alleviate their worries, and involving them to the extent that they want to be involved.

16. Handling crises of problem behaviors and rechoreographing (and rechoreographing and rechoreographing) 24/7 positive behavioral support $_{\mathrm{s}}$, and quality of life considerations for JT, his primary and weekend housemates, and our family' in light of what is learned from each crisis.

17. Addressing a lesser tasks and challenges too numerous to include.

For a couple of months, each of us invested about 15 hours per week in setting up JT's self-determination life of quality. That is in addition too two more than full-time jobs, two other children, and an elderly parent in need of daily caretaking. It is ironic that in order to envision and strive for individual and family quality of life, one's own quality of life can be negatively impacted in the process! It goes without saying that we believe the ends justify the means, that ultimately there is the benefit of enhanced quality of life for us all. We do what needs to be done without question and lovingly. However, few people admit the serious impact on quality of life for some family members in the pursuit of self-determination and long-term gain in quality of life for individuals with significant cognitive disabilities.

As a field, let us embrace the complexity of how difficult it is for individuals with significant cognitive disabilities and their families (and we ae hardly a prototypic family!) to be self-determined, to have selfdetermined trusted allies (family, friends, professional colleagues, and housemates), and to achieve quality of life (in light of significant cognitive, emotional, and behavioral challenges). Let us also acknowledge that as the risk, irreversibility, and intrusiveness of complex decisions (about anything) increase, we must surround self-determination with extensive or pervasive support. Finally, let us admit how little we know about genuinely involving individuals with significant cognitive disabilities in this complicated, but vitally important, process.

\section{Summary and Recommendations}

There has been insufficient progress in advancing selfdetermination for individuals with significant cognitive disabilities and their families. However, there is every reason to be optimistic that the field can make significant progress in embracing the complexities of significant cognitive disabilities, honoring family and individual culture, and developing and sustaining a self determined vision for quality of life over the person's full lifespan. Our accountability should not be measured in terms of numbers of our publications, conferences, or grants funded, but in the numbers of individuals with significant cognitive 
disabilities who experience quality of life consistent with their own values, preferences, strengths, and needs. To this end, we humbly make the following recommendations.

\section{Research}

1. Research should be conducted to conceptualize and operationalize self-determination from the perspectives of individuals with significant cognitive disabilities and their families representing a broad range of cultural and linguistic diversity. This research should be carried out in partnership with families and the trusted allies of individuals with significant cognitive disabilities and should employ participatory action research approaches (Santelli, Singer, DiVenere, Ginsberg, \& Powers, 1998; Turnbull, Friesen, \& Ramirez, 1998).

2. Research should be based on the "wisdom of the grassroots," locating and describing innovative models that have been created at the family level by individuals and their trusted allies.

\section{Partnerships}

1. Partnerships should be developed with national parent coalitions, including the 75 federally funded parent training and information centers (www.taaliance.org), the nearly 20 voluntary statewide Parent to Parent programs (www. parenttoparent.org), and the 16 grassroots consortiums (www.gcod.org; comprised of families representing a broad range of cultural and linguistic diversity) to help inform the national self-determination agenda related to family and individual cultural perspectives on self-determination.

2. Siblings of individuals with significant cognitive disabilities should be actively involved because they typically have the longest family relationship with the individual who has a significant cognitive disability.

3. Families characterized by a broad range of cultural and linguistic diversity should be represented in publications (e.g., journals, newsletters) and national/state conferences addressing issues related to self-determination.

\section{Service Provision}

1. A collaborative agenda should be developed expeditiously to integrate state of the art practice related to the five initiatives of quality of life enhancement for individuals; quality of life enhancement for families, comprehensive lifestyle implementation of positive behavioral supports, self-determination skills and motivation enhancement, and selfdetermination (individualized) funding.

2. State of the art adult broker agencies should be developed to support individuals with significant cognitive disabilities (receiving individualized funding) and their families to work with the providers to achieve quality of life consistent with their own values, preferences, strengths, and needs.

3. Efficient and streamlined state and federal funding should be developed or enlarged (as appropriate) to enable families (without our atypical advantages of six university degrees) to easily secure a selfdetermined quality of life, one that is consistent with the individual's (JT's) and their (our) values.

\section{References}

Bambara, L. M., Cole, C. L., \& Koger, F. (1998). Translating selfdetermination concepts into support for adults with severe disabilities. The Association for Persons with Severe Handicaps, 23 (1), 27-37.

Boggs, E. M. (1985). Who is putting whose head in the sand? (Or in the clouds, as the case may be). In H. R. Turnbull \& A. P. Turnbull (Eds.), Parents speak out: Then and now (2nded.pp.3953). Columbus, $\mathrm{OH}$ : Merrill.

Brown, R. I. (1996). Quality of life issues for students and families. Proceedings of the Queensland Guidance and Counseling Association 9th Conference, Brisbane.

Carr, E. G., Horner, R. H., Turnbull, A. P., Marquis, J. G., Magito-McLaughlin, D., McAtee, M. L., Smith, C. E., Ryan, K. A., Ruef, M. B., \& Doolabh, A. (1999). Positive behavior support as an approach for dealing with problem behavior in people with developmental disabilities: A research synthesis. Washington, DC: American Association on Mental Retardation.

Dinnerstein, R. D., Herr, S. S., \& O'Sullivan, J. L. (1999). A guide to consent. Washington, DC: American Association on Mental Retardation.

Felce, D. (1997). Defining and applying the concept of quality of life. Journal of Intellectual Disability Research, 41, 126135.

Gardner, J. F., \& Nudler, S. (1999). Quality performance in human services: Leadership, values, and vision. Baltimore, $\mathrm{MD}$ : Paul H. Brookes.

Hanson, M. J. (1998). Families with Anglo-European roots. In E. W. Lynch \& M. J. Hanson (Eds.), A guide for working with children and their families: Developing cross-cultural competence (pp. 93 126). Baltimore: Paul H. Brookes.

Hill, R. (1993). Culturally and linguistically diverse teachers in special education: Repairing or redesigning the leaky pipeline. Teacher Education and Special Education, 16 (3), 258260.

Horner, R. H., \& Carr, E. G. (1997). Behavioral support for students with severe disabilities: Functional assessment and comprehensive intervention. The Journal of Special Education, 31 (1), 84-104.

Kalyanpur, M., \& Harry, B. (1999). Culture in special education. Baltimore: Paul H. Brookes.

Luckasson, R., Coulter, D. L., Polloway, E. A., Reiss, S., Schalock, R. L., Snell, M. E., Spitalnik, D. M., \& Stark, J. A. (1992). Mental retardation: Definition, classification, and systems of supports (9th ed.). Washington, DC: American Association on Mental Retardation.

Nerney, T. (1999). The poverty of human services: An introduction. In T. Nerney \& D. Shumway (Eds.), The importance of income (pp. 2-14). Concord, NH: Institute on Disability, University of New Hampshire. 
Renwick, R., Brown, L., \& Nagler, M. (Eds.). (1996). Quality of life in health promotion and rehabilitation: Conceptual approaches, issues, and applications. Thousand Oaks, CA: Sage.

Santelli, B., Singer, G. H. S., DiVenere, N., Ginsberg, C., \& Powers, L. (1998). Participatory action research: Reflections on critical incidents in a PAR project. The Journal of the Association for Persons with Severe Handicaps, 23 (2), 211222

Schalock, R. L. (Ed.). (1996). Quality of life: Volume I. Conceptualization and measurement. Washington, DC: American Association on Mental Retardation.

Schalock, R. L. (Ed.). (1997). Quality of life: Volume II. Application to persons with disabilities. Washington, DC: American Association on Mental Retardation.

Schalock, R. L. (2000). Three decades of quality of life. In M. Wehmeyer \& J. Patton (Eds.), Mental retardation in the 21 st century (pp. 335-356). Austin: Pro-Ed.

Shumway, D. L. (1999). Freedom, support, authority, and responsibility: The Robert Wood Johnson Foundation national program on self-determination. Focus on Autism arid other Developmental Disabilities, 14 (1), 28-35.

Turnbull, A. P., \& Turnbull, H. R. et al. (2000, August). Family quality of life in the United States. Paper presented at the meeting of the International Association for the Scientific Study of Intellectual Disability, Seattle, WA.

Tunrbull, A. P., Blue-Banning, M., Turbiville, W., \& Park, J. (1999). From parent education to partnership education: A call for a transformed focus. Topics in Early Childhood Special Education, 19 (3), 164-172.

Turnbull, H. R., Bilken, D., Boggs, E., Ellis, J., Keeran, V., \& Siedor, G. (1977). Consent handbook. Washington, DC: American Association on Mental Retardation.

Turnbull, A. P., Friesen, B. J., \& Ramirez, C. (1998). Participatory action research as a model of conducting family re search. Journal of The Association for Persons with Severe Handicaps, 23 (3), 178-188.

Turnbull, A. P., \& Turnbull, H. R. (1985). Developing independence. Journal of Adolescent Health Care, 6 (2), 108119.

Turnbull, A. P., \& Turnbull, H. R. (1996). Self-determination within a culturally responsive family systems perspective: Balancing the family mobile. In L. E. Powers, G. H. S. Singer, \& J. A. Sowers (Eds.), On the road to autonomy: Promoting self-competence among children and youth with disabilities (pp. 195-200). Baltimore: Paul H. Brookes.

Turnbull, A. P., \& Turnbull, H. R. (1997). Families, professionals, and exceptionality: A special partnership (3rd ed.). Upper Saddle River, NJ: Merrill/Prentice Hall.

Turnbull, A. P., \& Turnbull, H. R. (2001). Families, professionals, and exceptionality. Collaborating for empowerment. Upper Saddle River, NJ: Merrill/Prentice Hall.

Wehmeyer, M.L. (1998). Self-determination and individuals with significant disabilities: Examining meanings and misinterpretations. Journal of The Association for Persons with Severe Handicaps, $23(1), 516$.

Wehmeyer, M. L. (1999). A functional model of selfdetermination:. Describing development and implementing instruction. Focus on Autism and Other Developmental Disabilities, 14 (1), 53-61.

Wehmeyer, M. L., Agran, M., \& Hughes, C. (1998). Teaching self-determination to students with disabilities: Basic skills for successful transition. Baltimore: Brookes.

Wehmeyer, M. L., \& Sands, D. J. (1998). Making it happen: Student involvement in education planning, decision making, and instruction. Baltimore: Paul H. Brookes.

Article received: May 1, 2000

Final acceptance: July 27, 2000 Editor

in charge: Linda M. Bambara

This research was supported by a grant from the National Institute on Disability and Rehabilitation Research to the Beach Center on Disability, Grant \#H133B980050. 